Jurnal ECOTIPE, Vol. 7, No.2, Oktober 2020, Hal. 85-91

p-ISSN 2355-5068, e-ISSN 2622-4852

Akreditasi Kemenristekdikti (SINTA 4), SK. No.10/E/KPT/2019

DOI: 10.33019/jurnalecotipe.v7i2.1902

\title{
Penerapan Kernel Jamak pada Program Berbasis PCA untuk Pengenalan Wajah dengan Variasi Iluminasi
}

\author{
Riko Arlando Saragih ${ }^{1}$, Tio Dewantho Sunoto ${ }^{2}$, Judea Janoto Jarden ${ }^{3}$, Dzakki Muhammad Hanif ${ }^{4}$ \\ Program Studi Teknik Elektro Universitas Kristen Maranatha ${ }^{1}$ \\ Program Studi Teknik Elektro Universitas Kristen Maranatha ${ }^{2}$ \\ Program Studi Teknik Elektro Universitas Kristen Maranatha ${ }^{3}$ \\ Program Studi Teknik Elektro Universitas Kristen Maranatha ${ }^{4}$ \\ *riko.as@eng.maranatha.edu ${ }^{1}$
}

\begin{abstract}
The application of kernel functions can solve the problem of non-linear image data so that the data can be linearly separable with a hyperplane by mapping the input space to the feature space to increase its dimensions. This article will discuss the improvement in recognition accuracy obtained by implementing multiple kernels in a PCA based program using linear, polynomial, and Gaussian kernels for facial recognition with illumination variations. The matching or recognition process is carried out using the SVM method. Improvements obtained from the application of multiple kernels will be compared with the implementation of a single kernel and see how much improvement of the accuracy. Based on the results of the implementation of multiple kernels, the average improvement in accuracy obtained from the face recognition results with illumination variations is $10.5 \%$ compared to a single kernel.
\end{abstract}

Keywords : Kernel functions, Multiple Kernels, PCA, SVM

\section{INTISARI}

Penerapan fungsi kernel dapat dilakukan untuk memecahkan masalah pada suatu data citra yang bersifat non-linier sehingga data tersebut dapat dipisahkan secara linier oleh sebuah hyperplane dengan cara melakukan pemetaan dari input space terhadap feature space untuk menaikkan dimensinya. Dalam artikel ini akan dibahas peningkatan akurasi pengenalan yang didapat dengan melakukan penerapan kernel jamak pada program berbasis PCA dengan menggunakan jenis kernel linear, polynomial, dan gaussian untuk pengenalan wajah yang diberi variasi pencahayaan. Proses pencocokan atau pengenalan identitas dilakukan dengan metode SVM. Peningkatan yang didapat dari hasil penerapan kernel jamak akan dibandingkan dengan penerapan kernel tunggal dan dilihat seberapa besar pengingkatan akurasi pengenalannya. Berdasarkan hasil penerapan kernel jamak yang dilakukan, rata-rata peningkatan akurasi yang didapatkan dari hasil pengenalan wajah dengan variasi pencahayaan adalah sebesar $10,5 \%$ dibandingkan dengan kernel tunggal.

Kata kunci: : Fungsi Kernel, Kernel Jamak, PCA, SVM

\section{PENDAHULUAN}

Terdapat banyak faktor yang mempengaruhi akurasi penentuan identitas seseorang pada pengembangan suatu algoritma sistem pengenalan wajah. Salah satu faktor yang mempersulit pengenalan adalah tingkat dan sudut pencahayaan yang berbeda [1],[2].Dibutuhkan pengembangan algoritma pengenalan wajah agar mampu mengenali wajah untuk kondisi yang dipengaruhi oleh faktor-faktor yang mempersulit pengenalan. Untuk itu diperlukan algortima pengenalan wajah yang robust untuk mengatasi kondisi yang real pada kehidupan sehari-hari [3].

Citra pada wajah manusia memiliki distribusi atau sebaran yang bersifat non-linier [4]. Oleh karena itu dibutuhkan suatu teknik sebagai solusi untuk masalah ini. Salah satunya adalah dengan teknik kernel (kernel trick). Kernel bekerja dengan cara pemetaan (mapping) data citra wajah terhadap ruang yang memiliki dimensi lebih tinggi, sehingga dapat melinierkan citra wajah [5]. Hasil yang didapat dari proses pelinieran tersebut 
Jurnal ECOTIPE, Vol. 7, No.2, Oktober 2020, Hal. 85-91

p-ISSN 2355-5068, e-ISSN 2622-4852

Akreditasi Kemenristekdikti (SINTA 4), SK. No.10/E/KPT/2019

DOI: 10.33019/jurnalecotipe.v7i2.1902

akan dilanjutkan dengan proses pencocokan (matching) [6].

Penerapan teknik pengenalan identitas seseorang melalui wajah dengan menggunakan kernel tunggal dapat mengatasi masalah ke-non-linieran citra wajah manusia [6]. Akurasi yang didapat dengan menggunakan teknik kernel tunggal masih belum cukup baik, karena pada teknik tersebut terdapat bias pada proses pelatihannya. Kernel jamak dikatakan dapat menghasilkan hasil yang lebih baik dibandingkan dengan kernel tunggal, dan telah banyak percobaan yang dilakukan terhadap kernel jamak pada banyak pengaplikasian [7]. Pada artikel ini akan dilakukan penerapan teknik kernel jamak (multiple kernels) untuk citra wajah pada pengenalan identitas seseorang berdasarkan citra wajah yang mengalami perubahan variasi pencahayaan.

\section{LANDASAN TEORI}

\section{A. Pengenalan Wajah}

Secara umum, sistem pengenalan wajah yang akan dirancang dalam artikel dapat dilihat dalam Gambar 1. Terdapat 3 proses utama dalam proses pengenalan wajah, yaitu proses deteksi wajah,

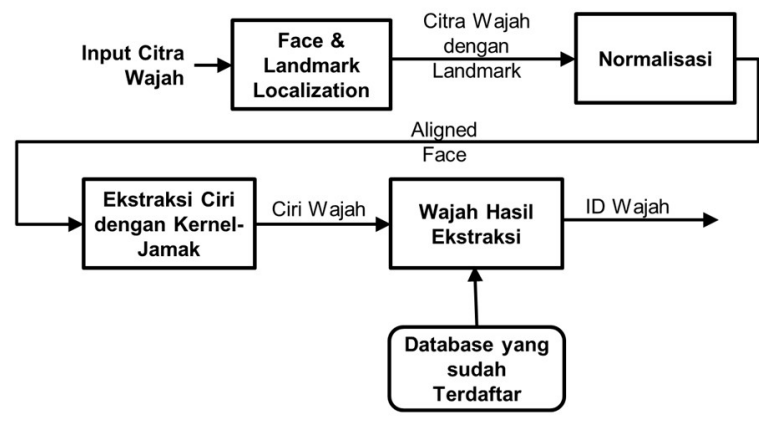

Gambar 1. Diagram blok pengenalan wajah secara umum dengan penerapan kernel

Deteksi wajah memisahkan area wajah dari latar belakang. Dalam video, wajah yang terdeteksi mungkin perlu dilacak pada beberapa frame menggunakan komponen face tracking. Sementara face detection memberikan perkiraan kasar tentang lokasi dan skala wajah, face landmarking melokalisasi landmark wajah (misalnya, mata, hidung, mulut, dan facial outline). Hal tersebut dapat dilakukan dengan modul landmarking atau modul face alignment.
Normalisasi wajah dilakukan untuk menormalkan wajah secara geometris dan fotometrik. Hal ini diperlukan karena metode pengenalan yang canggih diharapkan untuk mengenali gambar wajah dengan berbagai pose dan pencahayaan. Proses normalisasi geometri mengubah wajah menjadi bingkai standar dengan face cropping. Warping atau morphing dapat digunakan untuk normalisasi geometri yang lebih rumit. Proses normalisasi fotometrik menormalkan wajah berdasarkan pada sifat-sifat seperti pencahayaan dan grayscale.

Ekstraksi fitur wajah dilakukan pada wajah yang dinormalisasi untuk mengekstraksi informasi penting yang berguna untuk membedakan wajah orang yang berbeda dan robust terhadap variasi geometrik dan fotometrik. Fitur wajah yang diekstraksi digunakan untuk pencocokan wajah.

Dalam pencocokan wajah fitur yang diekstraksi dari wajah input dicocokkan dengan satu atau banyak wajah yang terdaftar dalam database. Pencocokan menghasilkan 'ya' atau 'tidak' untuk verifikasi 1:1; untuk identifikasi $1: \mathrm{N}$, output adalah identitas wajah input ketika pencocokan terbaik ditemukan dengan keyakinan yang cukup atau tidak diketahui ketika skor kecocokan di bawah threshold. Tantangan utama dalam tahap pengenalan wajah ini adalah menemukan kesamaan metrik yang cocok untuk membandingkan ciri wajah.

Akurasi pengenalan wajah sangat ditentukan oleh deskripsi/representasi citra wajah dan desain pengklasifikasi (classifier design). Representasi citra wajah yang diperoleh harus cukup diskriminatif dan deskriptor citra wajah juga diharapkan robust terhadap perubahan pencahayaan, pose, ekspresi, umur, jenis kelamin, ras, dan lain-lain, serta mudah mengekstraksinya dari sebuah citra wajah [4]. Selain itu, citra wajah akibat variasi pencahayaan dapat dikategorikan sebagai suatu jenis data non-linier [4].

\section{B. Teori tentang Kernel}

Kernel yang dimaksud dalam artikel ini adalah sebuah fungsi non-linier yang diterapkan ke dalam sekumpulan data yang bersifat non-linier (fungsi kernel), sehingga memudahkan pemetaan data tersebut [5]. Kernel juga bisa dikatakan dengan sebuah fungsi $\mathrm{K}$ yang untuk setiap $\mathrm{x}, \mathrm{z} \in \mathrm{X} . \mathrm{K}(\mathrm{x}, \mathrm{z})=\langle\phi(\mathrm{x}), \phi(\mathrm{z})\rangle$, dengan $\phi$ merupakan pemetaan dari $\mathrm{X}$ ke sebuah (inner products) ruang fitur $\mathrm{F}, \phi: \mathrm{x} \mapsto \phi(\mathrm{x}) \in \mathrm{F}$. Untuk model 
Jurnal ECOTIPE, Vol. 7, No.2, Oktober 2020, Hal. 85-91

p-ISSN 2355-5068, e-ISSN 2622-4852

Akreditasi Kemenristekdikti (SINTA 4), SK. No.10/E/KPT/2019

DOI: 10.33019/jurnalecotipe.v7i2.1902

yang berdasarkan pemetaan feature space $\phi(\mathrm{x})$ yang fixed nonlinear, fungsi kernel diberikan dengan relasi $\mathrm{k}\left(\mathrm{x}, \mathrm{x}^{\prime}\right)=\phi(\mathrm{x}) \mathrm{T} \phi\left(\mathrm{x}^{\prime}\right)[8]$.

Dalam prosesnya, terdapat empat aspek utama untuk pendekatan yang dilakukan ketika menerapkan fungsi kernel dan metode kernel, yaitu :

1. Komponen data ditempelkan (embedded) ke dalam ruang vektor yang dikatakan dengan ruang fitur.

2. Relasi linier dicari di antara citra yang dipetakan di ruang fitur.

3. Algoritma diimplementasikan sedemikian rupa agar koordinat komponen data yang ditempelkan (embedded) tidak diperlukan. Yang diperlukan hanya inner product- nya saja.

4. Pasangan inner product dapat dicari secara langsung dari data orisinil dengan menggunakan fungsi kernel.

Penggambaran fungsi kernel, fungsi yang menyisipkan data kepada sebuah feature space yang menghasilkan pola linier yang dipetakan agar menjadi terlihat linier dapat dilihat pada Gambar 2.

Pada penelitian ini, jenis kernel yang digunakan adalah kernel linear, polynomial, dan Gaussian, yang prosesnya akan dilanjutkan dengan pengaplikasian Principal Component Analysis (PCA) untuk mendapatkan kompponen principal dari data, agar dapat dikomputasikan dengan lebih cepat dengan tetap mempertahankan nilai-nilai pentingnya. Untuk bagian klasifikasinya, digunakan metode Support Vector Machine (SVM).

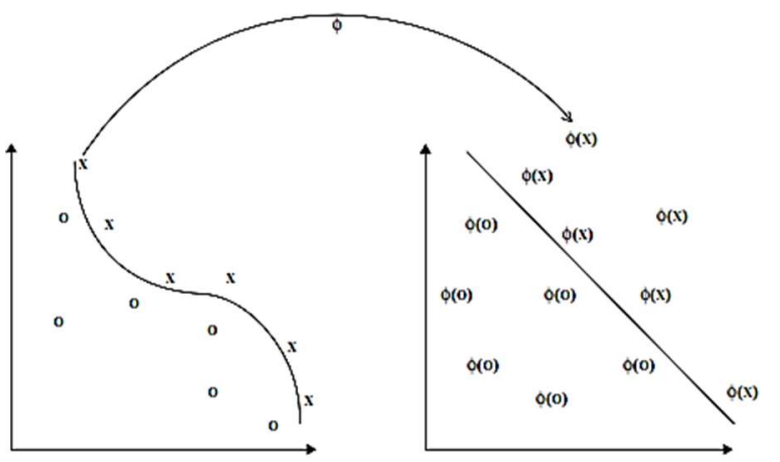

Gambar 2. Penggambaran Fungsi Kernel

Dalam penelitian ini akan direalisasikan suatu sistem pengenalan wajah dengan variasi pencahayaan dengan menerapkan penggunaan kernel jamak agar mendapatkan hasil yang lebih baik dibandingkan penerapan kernel tunggal $[7,9,10,11]$.

\section{METODE PENELITIAN}

Dalam merepresentasikan citra wajah akibat variasi pencahayaan, pose, dan ekspresi pada penelitian ini adalah dengan menggunakan kernel jamak, maka sifat/properti kunci dalam melakukan pelatihan kernel jamak yang akan dipilih dan dilakukan adalah sebagai berikut [7]:

1. Metode pelatihan untuk mengkombinasikan fungsi kernel adalah dengan menggunakan prinsip fixed-rules, yaitu fungsi yang tidak memiliki parameter dan tidak membutuhkan pelatihan.

2. Bentuk untuk mengkombinasikan fungsi kernel adalah dengan menggunakan aturan kombinasi linier dengan kategori weighted sum seperti berikut:

$k_{\eta}\left(x_{i}, x_{j}\right)=f_{\eta}\left(\left\{k_{m}\left(x_{i}^{m}, x_{j}^{m}\right)\right\}_{m=1}^{P} \mid \eta\right)=$ $\sum_{m=1}^{P} \eta_{m} k_{m}\left(x_{i}^{m}, x_{j}^{m}\right)$

Dengan $k$ adalah notasi untuk jenis fungsi kernel, $\eta$ menyatakan bobot dari masing-masing kernel, $f$ adalah fungsi untuk menggabungkan kernel, dan $P$ adalah banyaknya representasi ciri. $x_{i}=$ $\left\{x_{i}^{m}\right\}_{m=1}^{P}$ adalah data citra wajah.

3. Fungsi tujuan (target function) menggunakan kategori similarity-based functions, yang berfungsi menghitung ukuran kemiripan (similarity metric) antara matriks kernel yang digabungkan (dikombinasikan) dengan matriks kernel optimal yang dihitung dari data latih dan memilih kombinasi parameter fungsi yang memaksimalkan kemiripan.

4. Metode pelatihan adalah menggunakan satu tahap, yaitu menghitung secara langsung kombinasi dari parameter fungsi dan parameter dari kombinasi base learner sekaligus secara bersamaan.

5. Base learner yang digunakan di dalam penelitian ini adalah SVM (Support Vector Machine).

6. Kerumitan komputasi dari algoritma MKL utamanya bergantung pada metoda trainingnya (one step atau two steps) dan kerumitan komputasi dari base learner-nya. One-step method menggunakan fixed rules dan heuristics secara 
Jurnal ECOTIPE, Vol. 7, No.2, Oktober 2020, Hal. 85-91

p-ISSN 2355-5068, e-ISSN 2622-4852

Akreditasi Kemenristekdikti (SINTA 4), SK. No.10/E/KPT/2019

DOI: 10.33019/jurnalecotipe.v7i2.1902

umum tidak menghabiskan banyak waktu untuk mencari kombinasi parameter fungsi, dan juga secara kerumitan menyeluruh ditentukan oleh kerumitan dari base learner-nya secara garis besar.

Rancangan penerapan kernel jamak untuk pengenalan wajah akibat variasi pencahayaan yang direalisasikan dapat dilihat pada Gambar 3. Gambar 3 menunjukkan proses perancangan percobaan yang dilakukan.

Program yang digunakan untuk percobaan terdiri dari 3 buah program, yaitu PCA (Principal Component Analysis), KPCA (PCA dengan menggunakan kernel tunggal), dan MKPCA (PCA dengan menggunakan kernel jamak).

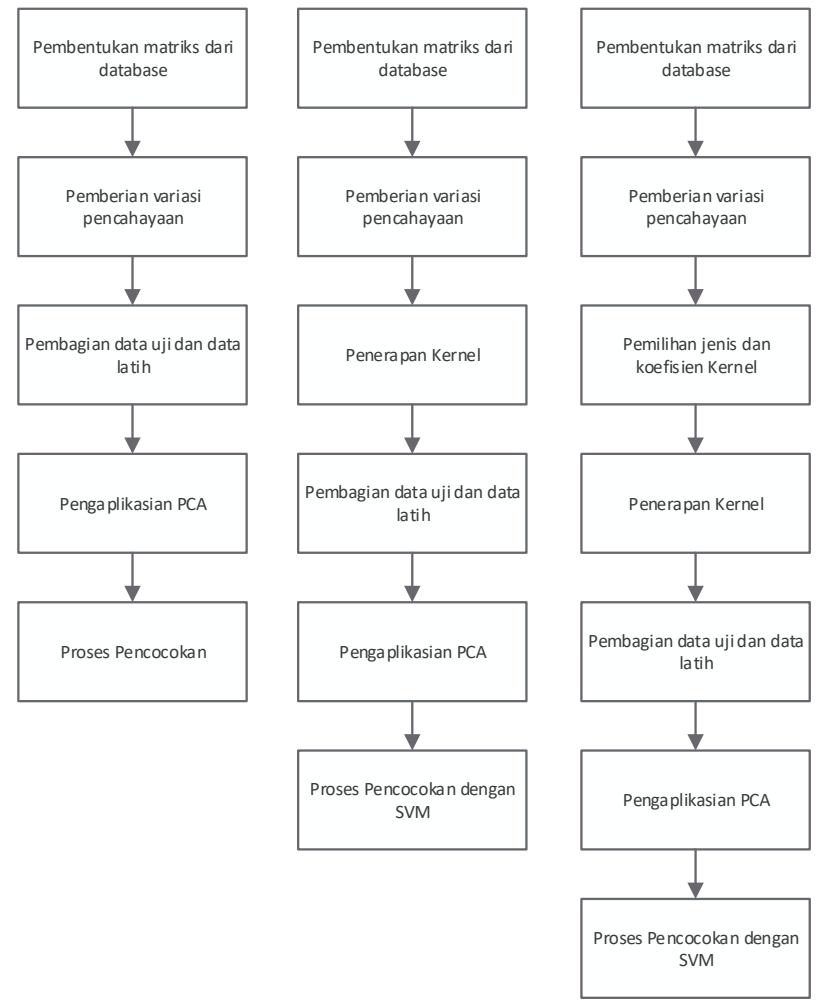

Gambar 3. Diagram Blok Sistem

\section{HASIL PENELITIAN DAN PEMBAHASAN}

Variasi pencahayaan dilakukan hanya pada data uji. Untuk data latih tidak dilakukan proses pemberian variasi pencahayaan. Ada tiga simulasi yang dilakukan untuk dua buah percobaan.

Pertama, untuk pemilihan kernel tunggal dan kombinasi kernel jamak mana yang terbaik, dilakukan dengan pemberian variasi pada ukuran citra $(32 \times 32$ dan 64x64), perbandingan jumlah data latih dengan jumlah data uji, dan pengubahan besarnya nilai eigen. Percobaan kedua, yaitu dengan memberikan variasi pencahayaan menggunakan kernel terbaik yang didapatkan dari percobaan pertama. Variasi yang dilakukan pada percobaan kedua berupa arah pencahayaan dan intensitas cahaya yang diberikan. Intensitas dan arah pencahayaan dilakukan dengan menggunakan perangkat lunak.

Dalam penerapan kernel jamak, proses penerapan kernel dilakukan sebanyak dua kali dengan jenis kernel yang berbeda lalu dikombinasikan. Terakhir akan diaplikasikan PCA dan diklasifikasi dengan menggunakan SVM untuk akhirnya mendapatkan perhitungan akurasi pengenalan wajah.

Seluruh citra pada database akan diekstraksi menjadi sebuah matriks yang berisikan data dari keseluruhan data input. Penerapan kernel akan dilakukan terhadap matriks database tersebut dengan cara dipetakan ke dimensi yang lebih tinggi daripada inputnya, dari input space dipetakan terhadap feature space agar data dapat dipisahkan secara linier dan dapat diklasifikasi.

Percobaan pertama dilakukan untuk menentukan kernel tunggal dan kernel jamak terbaik di antara jenis kernel yang digunakan, dan nantinya kernel tunggal dan kernel jamak tersebut akan digunakan untuk percobaan dengan variasi pencahayaan. Percobaan yang dilakukan pertama dilakukan dengan mengambil semua nilai eigen, sementara dalam percobaan berikut dilakukan pemilihan besarnya nilai eigen tertentu untuk mendapat hasil yang lebih baik.

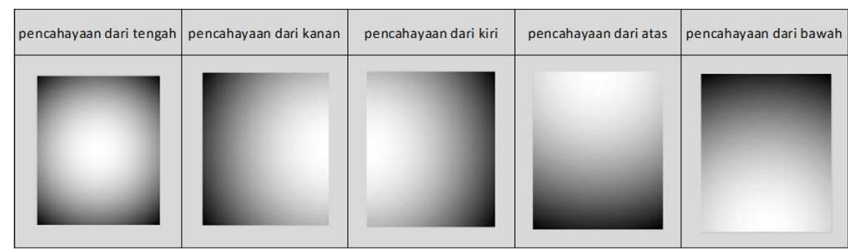

Gambar 4. Contoh visualisasi proses pengenalan

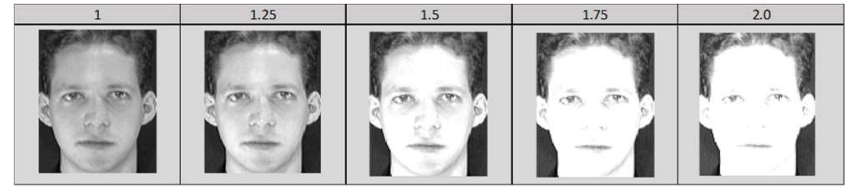

Gambar 5. Variasi Intensitas Pencahayaan yang Dilakukan 
Jurnal ECOTIPE, Vol. 7, No.2, Oktober 2020, Hal. 85-91

p-ISSN 2355-5068, e-ISSN 2622-4852

Akreditasi Kemenristekdikti (SINTA 4), SK. No.10/E/KPT/2019

DOI: 10.33019/jurnalecotipe.v7i2.1902

Gambar 4 memperlihatkan contoh visualisasi proses pengenalan wajah yang dilakukan. Sedangkan Gambar 5 menunjukkan gambaran variasi arah pencahayaan yang dilakukan dalam percobaan.

Tabel 1. Variasi Intensitas Pencahayaan yang Dilakukan

\begin{tabular}{|c|c|c|c|}
\hline NO & Citra yang diuji & Dikenali sebagai & Keterangan \\
\hline 1 & Subjek 1 & Subjek 1 & Benar \\
\hline 2 & Subjek 1 & Subjek 29 & Tidak Benar \\
\hline$\vdots$ & & $\vdots$ & $\vdots$ \\
\hline 319 & Subjek 40 & Subjek 40 & Benar \\
\hline 320 & Subjek 40 & Subjek 40 & Benar \\
\hline
\end{tabular}

Hasil yang didapatkan, kernel tunggal terbaik adalah kernel polynomial, dan kombinasi kernel jamak terbaik adalah kernel linear+polynomial. Kedua pilihan tersebut digunakan untuk melakukan percobaan selanjutnya.

Untuk hasil eksperimen pertama, merupakan hasil awal dari tiga jenis program untuk mendapatkan pemilihan jenis kernel yang paling baik dari percobaan yang dilakukan untuk data lebih lengkapnya terdapat pada Tabel 2 untuk ukuran citra 32×32 dan Tabel 3 untuk ukuran citra $64 \times 64$.

Tabel 2. Hasil Percobaan PCA, KPCA, dan MKPCA dengan Mengubah Banyaknya Nilai Eigen (32×32)

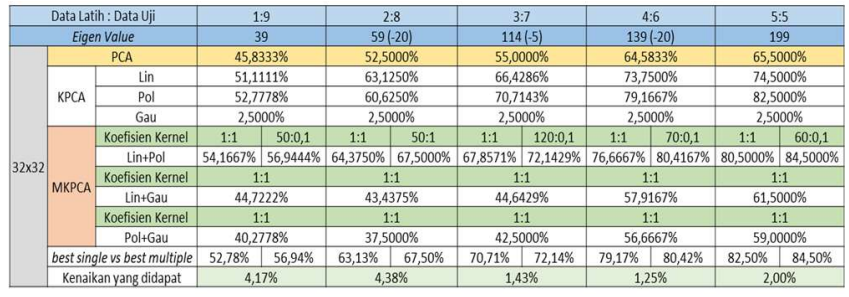

Tabel 3. Hasil Percobaan PCA, KPCA, dan MKPCA dengan Mengubah Banyaknya Nilai Eigen (64x64)

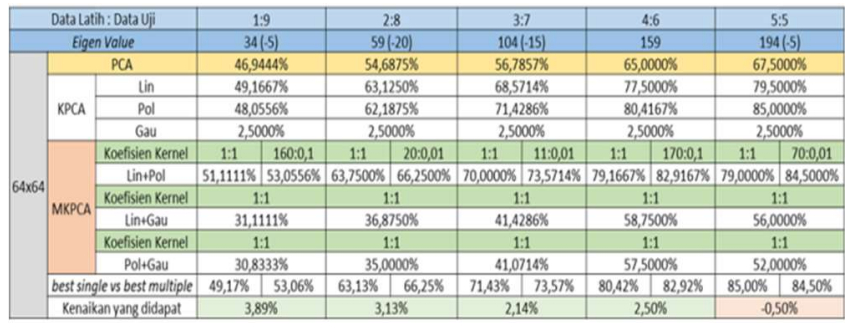

Seluruh tabel di bawah ini, merupakan hasil percobaan yang telah didapatkan setelah menerapkan variasi pencahayaan dari berbagai sisi dan intensitas cahaya.

Tabel 4. Hasil Percobaan Variasi Pencahayaan dari Tengah

\begin{tabular}{|c|c|c|c|c|c|c|}
\hline \multicolumn{7}{|c|}{ Pencahayaan dari tengah } \\
\hline \multirow{3}{*}{ Intensitas } & \multirow{3}{*}{ PCA } & \multirow{3}{*}{$\begin{array}{c}\text { KPCA } \\
\text { (Polynomial) }\end{array}$} & \multicolumn{3}{|c|}{ mKPCA } & \multirow{3}{*}{$\begin{array}{l}\text { Peningkatan jamak vs } \\
\text { tunggal }\end{array}$} \\
\hline & & & \multicolumn{3}{|c|}{ (bobotkoefisien kemel Limear: Polymomial) } & \\
\hline & & & 1:1 & \multicolumn{2}{|c|}{ tuningkoefisien } & \\
\hline 1.0 & $2,9617 \%$ & $5,0000 \%$ & $2,5000 \%$ & $10000: 0,001$ & $13,7500 \%$ & $8,7500 \%$ \\
\hline 1.25 & $6,2500 \%$ & $10,0000 \%$ & $5,0000 \%$ & $200: 0,01$ & $22,0833 \%$ & $12,0833 \%$ \\
\hline 1.5 & $6,2500 \%$ & $13,7500 \%$ & $7,5000 \%$ & $1000: 0,1$ & $24,5833 \%$ & $10,8333 \%$ \\
\hline 1.75 & $4,5833 \%$ & $14,1667 \%$ & $10,8333 \%$ & $500: 0,1$ & $23,3333 \%$ & $9,1666 \%$ \\
\hline 2.0 & $7,0833 \%$ & $20,0000 \%$ & $12,9167 \%$ & $630: 0,1$ & $31,6667 \%$ & $11,6667 \%$ \\
\hline
\end{tabular}

Tabel 5. Hasil Percobaan Variasi Pencahayaan dari Kanan

\begin{tabular}{|c|c|c|c|c|c|c|}
\hline \multicolumn{7}{|c|}{ Pencahayaan dari kanan } \\
\hline \multirow{3}{*}{ Intensitas } & \multirow{3}{*}{ PCA } & \multirow{3}{*}{$\begin{array}{c}\text { KPCA } \\
\text { (Polynomial) }\end{array}$} & \multicolumn{3}{|c|}{$\mathrm{mKPCA}$} & \multirow{3}{*}{$\begin{array}{c}\text { Peningkatan jamak vs } \\
\text { tunggal }\end{array}$} \\
\hline & & & \multicolumn{3}{|c|}{ (bobot/koefisien kernel Limear: Polynomial) } & \\
\hline & & & 1:1 & \multicolumn{2}{|c|}{ tuning koefisien } & \\
\hline 1.0 & $2,5000 \%$ & $2,5000 \%$ & $2,5000 \%$ & $10000: 0,001$ & $3,3000 \%$ & $0,8000 \%$ \\
\hline 1.25 & $4,5833 \%$ & $5,4167 \%$ & $2,5000 \%$ & $10000: 0,01$ & $10,8333 \%$ & $5,4166 \%$ \\
\hline 1.5 & $4,5833 \%$ & $15,8333 \%$ & $5,0000 \%$ & $5000: 0,01$ & $37,0833 \%$ & $21,2500 \%$ \\
\hline 1.75 & $7,9167 \%$ & $28,7500 \%$ & $13,7500 \%$ & $1000: 0,01$ & $46,2500 \%$ & $17,5000 \%$ \\
\hline 2.0 & $7,9167 \%$ & $37,5000 \%$ & $22,5000 \%$ & $1000: 0,01$ & $50,4167 \%$ & $12,9167 \%$ \\
\hline
\end{tabular}

Tabel 5. Hasil Percobaan Variasi Pencahayaan dari Kiri

\begin{tabular}{|c|c|c|c|c|c|c|}
\hline \multicolumn{7}{|c|}{ Pencahayaan dari kiri } \\
\hline \multirow{3}{*}{ Intensitas } & \multirow{3}{*}{ PCA } & \multirow{3}{*}{$\mid \begin{array}{c}\text { KPCA } \\
\text { (Polymomial) }\end{array}$} & \multicolumn{3}{|c|}{ mKPCA } & \multirow{3}{*}{$\begin{array}{c}\text { Peningkatan jamak vs } \\
\text { tunggal }\end{array}$} \\
\hline & & & \multicolumn{3}{|c|}{ (bobotkoefisien kernel Limear: Polynomial) } & \\
\hline & & & 1:1 & \multicolumn{2}{|c|}{ tuningkoefisien } & \\
\hline 1.0 & $2,0833 \%$ & $2,5000 \%$ & $2,5000 \%$ & $10000: 0,01$ & $10,4167 \%$ & $7,9167 \%$ \\
\hline 1.25 & $4,1667 \%$ & $9,1667 \%$ & $2,5000 \%$ & $2000: 0,01$ & $17,9167 \%$ & $8,7500 \%$ \\
\hline 1.5 & $6,6667 \%$ & $7,9167 \%$ & $8,7500 \%$ & $7000: 0,01$ & $16,6667 \%$ & $8,7500 \%$ \\
\hline 1.75 & $9,5833 \%$ & $16,2500 \%$ & $18,7500 \%$ & $1000: 0,01$ & $28,3333 \%$ & $12,0833 \%$ \\
\hline 2.0 & $3,7500 \%$ & $16,2500 \%$ & $16,6667 \%$ & $10000: 0,01$ & $29,1667 \%$ & $12,9167 \%$ \\
\hline
\end{tabular}

Tabel 6. Hasil Percobaan Variasi Pencahayaan dari Atas

\begin{tabular}{|c|c|c|c|c|c|c|}
\hline \multicolumn{7}{|c|}{ Pencahayaan dari atas } \\
\hline \multirow{3}{*}{$\begin{array}{c}\text { Intensita } \\
\mathrm{s}\end{array}$} & \multirow{3}{*}{ PCA } & \multirow{3}{*}{$\begin{array}{c}\text { KPCA } \\
\text { (Polynomial) }\end{array}$} & \multicolumn{3}{|c|}{$\mathrm{mKPCA}$} & \multirow{3}{*}{$\begin{array}{c}\text { Peningkatan jamak vs } \\
\text { tunggal }\end{array}$} \\
\hline & & & \multicolumn{3}{|c|}{ (bobot/koefisien kemel Linear: Polynomial) } & \\
\hline & & & 1:1 & \multicolumn{2}{|c|}{ tuming koefisien } & \\
\hline 1.0 & $3,7500 \%$ & $13,7500 \%$ & $3,7500 \%$ & $5000: 0,01$ & $31,2500 \%$ & $17,5000 \%$ \\
\hline 1.25 & $10,0000 \%$ & $26,6667 \%$ & $14,5833 \%$ & $4000: 0,01$ & $44,5833 \%$ & $17,9166 \%$ \\
\hline 1.5 & $11,6667 \%$ & $25,8333 \%$ & $16,2500 \%$ & $6000: 0,001$ & $38,3333 \%$ & $12,5000 \%$ \\
\hline 1.75 & $7,5000 \%$ & $20,0000 \%$ & $13,7500 \%$ & $300: 0,01$ & $25,4167 \%$ & $5,4167 \%$ \\
\hline 2.0 & $15,0000 \%$ & $21,2500 \%$ & $14,1667 \%$ & $1000: 0,01$ & $25,4167 \%$ & $4,1667 \%$ \\
\hline
\end{tabular}


Jurnal ECOTIPE, Vol. 7, No.2, Oktober 2020, Hal. 85-91

p-ISSN 2355-5068, e-ISSN 2622-4852

Akreditasi Kemenristekdikti (SINTA 4), SK. No.10/E/KPT/2019

DOI: 10.33019/jurnalecotipe.v7i2.1902

Tabel 7. Hasil Percobaan Variasi Pencahayaan dari Bawah

\begin{tabular}{|c|c|c|c|c|c|c|}
\hline \multicolumn{7}{|c|}{ Pencahayaan dari bawah } \\
\hline \multirow{3}{*}{ Intensitas } & \multirow{3}{*}{ PCA } & \multirow{3}{*}{$\begin{array}{c}\text { KPCA } \\
\text { (Polynomial) }\end{array}$} & \multicolumn{3}{|c|}{ mKPCA } & \multirow{3}{*}{$\begin{array}{l}\text { Peningkatan jamak vs } \\
\text { tunggal }\end{array}$} \\
\hline & & & \multicolumn{3}{|c|}{ (bobotkoefisien kemel Linear : Polynomial) } & \\
\hline & & & 1:1 & \multicolumn{2}{|c|}{ tuning koefisien } & \\
\hline 1.0 & $2,0833 \%$ & $2,5000 \%$ & $2,5000 \%$ & $3000: 0.01$ & $3,7500 \%$ & $1,2500 \%$ \\
\hline 1.25 & $2,0833 \%$ & $6,2500 \%$ & $2,5000 \%$ & $5000: 0,01$ & $15,0000 \%$ & $8,7500 \%$ \\
\hline 1.5 & $9,5833 \%$ & $20,8333 \%$ & $7,0833 \%$ & $700: 0,01$ & $35,0000 \%$ & $14,1667 \%$ \\
\hline 1.75 & $18,7500 \%$ & $33,7500 \%$ & $19,1667 \%$ & $900: 0,1$ & $45,8333 \%$ & $12,0833 \%$ \\
\hline 2.0 & $31,6667 \%$ & $44,5833 \%$ & $36,2500 \%$ & $900: 0,1$ & $52,1967 \%$ & $7,6134 \%$ \\
\hline
\end{tabular}

Dari seluruh tabel di atas, menunjukkan bahwa terjadi kenaikan akurasi pengenalan dari penggunaan kernel jamak. Pengaruh variasi pencahayaan cukup besar dalam pengenalan wajah, dan dapat ditingkatkan melalui penggunaan kernel jamak tersebut. Rata-rata peningkatan akurasi yang didapatkan pada seluruh percobaan di atas sebesar 10,486\%. Kenaikan paling rendah terdapat pada variasi pencahayaan dari kanan dengan intensitas 1,0, yaitu sebesar $0,8 \%$, sedangkan kenaikan tertinggi didapatkan pada variasi pencahayaan dari kanan dengan intensitas 1,5 yaitu sebesar $21,25 \%$.

Peningkatan akurasi yang didapatkan cenderung sedikit acak dan tidak memiliki pola yang pasti, karena variasi dari pencahayaan yang cukup beragam dan mungkin tergantung dari bagian dari citra yang terkena cahaya, serta beragamnya citra masukan dengan subyek yang beragam, tetapi secara keseluruhan semuanya memiliki peningkatan akurasi dengan menggunakan kernel jamak.

\section{KESIMPULAN}

Dari hasil yang telah diperoleh, dapat ditarik kesimpulan untuk eksperimen yang dilakukan. Dibutuhkan pemilihan kombinasi kernel dan koefisien/bobot yang tepat pada penggunaan kernel jamak agar mendapatkan hasil akurasi pencocokan yang maksimal. Hasil akurasi pencocokan paling maksimal didapatkan menggunakan metoda MKPCA dengan kombinasi kernel linear + polynomial. Variasi pencahayaan memiliki dampak atau pengaruh yang cukup besar terhadap akurasi pencocokan untuk pengenalan wajah. Peningkatan akurasi hasil pencocokan yang didapatkan dari seluruh percobaan variasi pencahayaan memiliki rata-rata peningkatan sebesar 10,486\%, dengan kenaikan akurasi paling besar terdapat pada variasi pencahayaan dari kanan dengan intensitas cahaya 1,5, kenaikan yang didapatkan sebesar 21.25\%. Metode penggunaan kernel jamak terbukti mampu meningkatkan akurasi pencocokan, walaupun membutuhkan penaan secara lebih tepat.

\section{Ucapan Terimakasih}

Penulis mengucapkan terima kasih untuk pendanaan internal dari LPPM Universitas Kristen Maranatha di dalam melakukan penelitian ini.

\section{DAFTAR PUSTAKA}

[1] A.S. Tolba, A.H. El-Baz, and A.A. El-Harby. 2006. Face Recognition : A Literature Review. International Journal of Signal Processing, Vol.2, No.2, pp.88-103.

[2] Tan, X., S. Chen, Z.-H Zhou, and F. Zhang. 2006. Face Recognition from a Single Image per Person: A Survey. Pattern Recognition, Vol. 39, pp. 1725-1745.

[3] G. Hua, M.-H. Yang, E. Learned-Miller, Y. Ma, M. Turk, D.J. Kriegman, and T. S. Huang. 2011. Introduction to the Special Section on Real-World Face Recognition. IEEE Transactions on Pattern Analysis and Machine Intelligence, Vol. 33, No.10, pp. 1921-1924.

[4] Li, S. Z. and A. K. Jain. 2011. Handbook of Face Recognition. Springer-Verlag London Limited.

[5] Shawe-Taylor, J., N. Christianini. 2004. Kernel Methods for Pattern Analysis.Cambridge University Press: U.S.A.

[6] Schölkopf, B., Smola, A. S., and K-R. Muller, 1998. Nonlinear component analysis as a kernel eigen value problem. Neural Comput. 10(5), 1299-1319.

[7] Gonen, M., E. Alpaydin. 2011. Multiple Kernel Learning Algorithms. Journal of Machine Learning Research, 12, 2211-2268.

[8] Bishop, C. M. 2006. Pattern Recognition and Machine Learning. New York : Springer.

[9] Sonnerburg, S., Ratsch, G., Schafer, C., and Schölkopf, B. 2006. Large Scale Multiple Kernel Learning. Journal of Machine Learning Research, 7, 1531-1565.

[10] Ming, Z., Bugeau, A., Rouas, J-L., and Shochi, T. 2015. Facial Action Units Intensity Estimation by the Fusion of Features with Multi-kernel Support 
Jurnal ECOTIPE, Vol. 7, No.2, Oktober 2020, Hal. 85-91

p-ISSN 2355-5068, e-ISSN 2622-4852

Akreditasi Kemenristekdikti (SINTA 4), SK. No.10/E/KPT/2019

DOI: 10.33019/jurnalecotipe.v7i2.1902

Vector Machine. $11^{\text {th }}$ International Conference and Workshops on Automatic Face and Gesture Recognition, 1-6

[11] Liu, Q. and Wang, C. 2017. Within-component and between-component multi-kernel discriminating correlation analysis for colour face recognition. IET Journals, Vol. 11, Issue 8, 663-674

[12] Lu, J., Wang, G., and Moulin, P. 2013. Image Set Classification Using Holistic Multiple Order Statistics Features and Localized Multi-Kernel Metric Learning. IEEE International on Conference Computer Vision, 329-336 